DOI: 10.38136/jgon.974427

\title{
Indirekt Hiperbilirubinemi Nedeni ile Tedavi Gerektiren Term Yenidoğanların Retrospektif Olarak Değerlendirilmesi
}

\section{Retrospective Evaluation of Term Newborns Requiring Treatment for Indirect Hyperbilirubinemia}

\section{Erbu YARCl \\ Didem ÖZTÜRK YARCI ${ }^{2}$}

${ }^{1}$ Dörtçelik Çocuk Hastanesi Yenidoğan Kliniği, Bursa, Türkiye

${ }^{1}$ Serbest Hekim, Kadın Hastalıkları ve Doğum, Bursa, Türkiye

\section{Öz}

Amaç: Yenidoğan döneminde görülen indirekt hiperbilirubinemi (IHB) sıklıkla fizyolojik olmakla birlikte şiddetli hiperbilirubinemiye bağı nörolojik hasar gelişebilir. Bu çalışmada, yenidoğan servisine sadece IHB tanısı ile yatırıarak tedavi edilen term yenidoğanların genel özellikleri, eşlik eden hastalıkları, nedenleri ve uygulanan tedaviler açısından değerlendirilmesi amaçlanmıştır.

Gereç ve Yöntemler: Çalışmaya 1 Mart 2018-1 Mart 2020 tarihleri arasında Yenidoğan Yoğun Bakım Servisi'nde IHB tanısı ile tedavi edilen 545 term yenidoğan dahil edildi. IHB tedavisi için fototerapi, intravenöz immünglobulin (IVIG) uygulaması ve kan değişimi kullanıldı.

Bulgular: IHB'nin en sık nedenleri sırası ile ABO uygunsuzluğu ( $n=156)$, anne sütü ile beslenememe $(n=127)$, bilinmeyen nedenler $(n=126)$ ve düşük doğum ağırlığı $(n=87)$ olarak saptandı. Hemolitik sarılığı olan yenidoğanlar etiyolojik olarak incelendiğinde en sık neden $\mathrm{ABO}$ uygunsuzluğu olup Rh uygunsuzluğu ve subgrup uygunsuzluğu diğer sık nedenleri oluşturmakta idi.

Sonuç: IHB yenidoğan döneminin sık görülen sorunlarından biri olup erken tanı, altta yatan nedenin zamanında belirlenmesi ve doğru hasta yönetimi prognoza etki eden en önemli faktörlerdir. Kan grubu uygunsuzluğu, düşük doğum ağırlğ̆ı, anne sütü ile beslenmedeki eksiklikler gibi altta yatan risk faktörlerinin dikkate alınarak izlem yapılması büyük öneme sahiptir.

Anahtar Kelimeler: Term Yenidoğan, İndirekt Hiperbilirubinemi, Fototerapi

\section{GíRiş}

İndirekt hiperbilirubinemi (İHB) doğumdan sonraki ilk bir hafta içinde yenidoğanların yaklaşık \%50'sinde görülen bir durumdur. Yenidoğan döneminde görülen İHB sıklıkla fizyolojik olmakla birlikte şiddetli hiperbilirubinemiye bağlı nörolojik hasar gelişebilir (1). Irk, coğrafi bölge, genetik özellikler, gestasyonel yaş, doğum ağırlığı ve bebeğin beslenme özellikleri hiperbilirubinemi şiddet ve süresini etkileyen faktörlerdir (2). Bunlara ek olarak maternal hastalıklar, yenidoğanın hemolitik hastalığı, neonatal
(1) Orcid ID:0000-0003-4434-0958

(1) Orcid ID:0000-0002-8979-5721

\section{ABSTRACT}

Aim: Although indirect hyperbilirubinemia (IHB) in the neonatal period is often physiological, it can cause severe neurological damage. We aimed to evaluate the characteristics, etiology and forms of treatment for term newborns hospitalized in the newborn intensive care unit (NICU) due to indirect hyperbilirubinemia.

Materials and Methods: 545 term newborns treated with a diagnosis of IHB between 1 March 2018 and 1 March 2020 in the NICU were included in the study. Phototherapy, intravenous immunoglobuline (IVIG) and exchange transfusion were used for the treatment of IHB.

Results: The most common causes of IHB were ABO incompatibility ( $n=156)$, inability to breastfeed ( $n=127)$, unknown reasons $(n=126)$ and low birth weight (LBW) $(n=87)$. In newborns with hemolytic jaundice, the most common cause was ABO incompatibility followed by Rh and subgroup incompatibility.

Conclusion: IHB is one of the most common problems of the newborn. Early diagnosis and proper management are the most important factors affecting the prognosis. Risk factors such as blood group incompatibility, LBW and deficiencies in breastfeeding must be kept in mind.

Keywords: Term newborn, Indirect hyperbilirubinemia, Phototherapy

sepsis ve konjenital enfeksiyonlar da diğer risk faktörleri arasında yer almaktadır (1). Tedavide çoğunlukla fototerapi yeterli olmakla birlikte, kan değişimi ve intavenöz immünglobulin (IVIG) tedavisi veya bu tedavi modalitelerinin birlikte kullanılması gerekebilmektedir (3).

Bu çalışmada, yenidoğan kliniğine sadece indirekt hiperbilirubinemi tanısı ile yatııılarak tedavi edilen term yenidoğanların genel özellikleri, eşlik eden hastalıkları, nedenleri ve uygulanan tedaviler açısından değerlendirilmesi amaçlanmıştır. 


\section{GEREÇ VE YÖNTEMLER}

Bu retrospektif ve tek merkezli çalışma 1 Mart 2018 ile 1 Mart 2020 tarihleri arasında Dörtçelik Çocuk Hastanesi Yenidoğan Yoğun Bakım Servisi'nde yürütülmüştür. Hastanede yatırılarak takip edilen hastaların yatış tanı ve çıkış sırasında oluşturulan epikriz dosyasında "ICD-10 Tanı Kodları" listesinde yenidoğan sarılığı ile ilişkili tanılar "P55.Fetüs ve yenidoğanın immün hemolitik hastalığı, P56.Hidrops fetalis, Hemolitik hastalığa bağlı, P57.Kernikterus, P58. Yenidoğan sarılıkları, diğer aşırı hemolize bağlı ve P59.Yenidoğan sarılığı, diğer ve tanımlanmamış nedenlere bağıı" açısından filtreleme yapılarak hastane elektronik kayit sistemi taranarak, bu filtreleme sonucu elde edilen hastaların epikriz dosyaları incelenerek sadece İHB tanısı ile fototerapi uygulanan, IVIG verilen veya kan değişimi yapılan gestasyonel yaşı 37 hafta ile 41 hafta 6 gün arasında olan yenidoğanlar çalışmaya dahil edildi. Başka nedenlerle izlenen yenidoğanların takipleri sırasında İHB gelişenler çalışmaya dahil edilmedi. Konjenital anomali veya malformasyonu olan (gastroşizis, konjenital diafram hernisi, kromozom anomalisi, kompleks konjenital kalp hastalığı gibi) ve aile onamı olmayan hastalar çalışma dışı bırakıldı.

Anne yaşı, eşlik eden maternal hastalıklar, gestasyonel yaş, doğum ağırlığı, gestasyonel yaşa göre doğum ağırlığı, doğum şekli, cinsiyet gibi demografik özelliklere ek olarak yatışta eşlik eden metabolik bozukluklar, beslenme bozukluğu da dosyadan incelenerek kayıt altına alındı. Doğum ağırığı 2500 gramın atındaki bebekler düşük doğum ağırlıkı (DDA) bebek olarak kabul edildi. Tedavi endikasyonu ve şekli gebelik haftası 35 hafta ve üzerinde olan bebeklerde gebelik haftası ve risk faktörlerini içeren eğriler kullanılarak belirlendi (4). IHB tedavisi için fototerapi, IVIG uygulaması ve kan değişimi kullanıldı.

Hastaların hemogram, serum total bilirubin ve albumin düzeyleri, periferik kan yayması, retikülosit sayımı, direkt coombs testi, anne ve bebek kan grubu, gerekli hastalarda subgrup analizi, serum elektrolit değerleri ve böbrek fonksiyon testleri değerlendirildi. Nedeni açıklanamayan hemoliz bulguları ve retikülositozu olan veya hematokrit değerinde düşme olan hastalardan glukoz-6-fosfat dehidrogenaz ve pirüvatkinaz enzim düzeyi için örnek gönderildi. Uzamış sarılık saptanan hastalarda etiyolojiye yönelik olarak karaciğer fonksiyon testleri, tiroid fonksiyon testleri, galaktozemi için idrarda redüktan madde, idrar tetkiki ve idrar kültürü gönderildi. Sonda ile alınan idrar kültüründe 100,000 koloni/ml üzerinde üreme olan hastalara idrar yolu enfeksiyonu tanısı konularak uygun tedavi verildi.
Bu çalışma için Uludağ Üniversitesi Tıp Fakültesi Klinik Araştırmalar Etik Kurulu'nun 09.12.2020 tarih ve 2020-22/3 karar numaralı onayı alınmıştır.

Elde edilen tüm veriler, SPSS sürüm 22.0 yazılımı (SPSS, Inc Chicago, IL, ABD) kullanılarak analiz edildi. Tanımlayıcı veriler için frekans (n), yüzde (\%), ortalama, standart sapma (SS), medyan, minimum ve maksimum değerler hesaplandı. Nicel değişkenlerin normal dağlıma uygunluğu Kolmogorov Smirnov testi ile değerlendirildi. Hemolitik sarılığı olan ve olmayan olgulardaki bilirubin düzeylerinin farklı olup olmadığının analizi için Pearson ki-kare testinden yararlanıldı. $P$ değeri $<0.05$ istatistiksel olarak anlamlı kabul edildi.

\section{BULGULAR}

Çalışmaya 545 term yenidoğan dahil edildi. Çalışmaya dahil edilen hastaların \%56'sını erkek yenidoğanlar oluşturmakta idi. Kız/erkek oranı 0.79 (240/305) olarak saptanan bebeklerin ve annelerin sosyo-demografik özellikleri Tablo 1'de gösterilmiştir.

Tablo 1. Yenidoğanların sosyo-demografik özellikleri

\begin{tabular}{lcc}
\hline Özellikler & $\begin{array}{c}\text { Ortalama } \pm \text { standart } \\
\text { sapma } \\
\mathbf{n} / \%\end{array}$ & Minimum-Maksimum \\
\hline Anne yaşı (yıl) & $28.3 \pm 5.9$ & $18-44$ \\
Gestasyonel yaş (hafta) & $38.4 \pm 1.2$ & $37-42$ \\
Doğum ağırlığı (gr) & $3122.4 \pm 563.9$ & $(1560-5080)$ \\
Postnatal yaş (gün) & $5.3 \pm 2.6$ & $(1-25)$ \\
Başvuru bilirubin değeri & $24.3 \pm 5.4$ & $(12-31)$ \\
(mg/dl) & & \\
Doğum şekli & $312(\% 57.2)$ & \\
$\quad$ Spontan vajinal yol & & \\
Cinsiyet & $305(\% 56)$ \\
$\quad$ Erkek & $66(\% 12)$ \\
SGA & $40(\% 7.3)$ \\
LGA & $35(\% 6.4)$ \\
Makrozomi & $38(\% 6.9)$ \\
Diyabetik anne bebeği & $300(\% 55.1)$ \\
Erken Term* & $245(\% 44.9)$ \\
Term ** & \\
* Son adet tarihine göre gestasyonel yaş 370 - 386/7 arası (28). \\
* Son adet tarihine göre gestasyonel yaş 390-416/7 arası (28). \\
\end{tabular}

İHB'nin en sık nedenleri sırası ile ABO uygunsuzluğu ( $n=156)$, anne sütü ile beslenememe ( $n=127)$, bilinmeyen nedenler $(n=126)$ ve DDA ( $n=87$ ) olarak saptandı. Hastalar IHB tanısı aldıktan sonra servise yatırılarak fototerapi başlandı ve etiyolojiye yönelik olarak tetkik edildi. Hastanın gereksinimi doğrultusunda kan değişimi ve/veya IVIG uygulandı. İHB'nin nedenleri Tablo 2'e özetlenmiştir. 
Tablo 2. Yenidoğanların İndirekt Hiperbilirubinemi Nedenleri

\begin{tabular}{lcccc}
\hline & $\begin{array}{c}\text { Erken } \\
\text { term* }\end{array}$ & Term** & & \\
\cline { 2 - 3 } Nedenler & $\mathbf{n}$ & $\mathbf{n}$ & Toplam & \% \\
\hline ABO uygunsuzluğu & 65 & 91 & 156 & 28.6 \\
Anne sütü ile beslenememe & 85 & 42 & 127 & 23.3 \\
Bilinmeyen nedenler & 56 & 60 & 126 & 23.1 \\
Düşük doğum ağırlığı & 73 & 14 & 87 & 16 \\
Rh uygunsuzluğu & 5 & 7 & 12 & 2.2 \\
Sepsis & 7 & 4 & 11 & 2 \\
İdrar yolu enfeksiyonu & 6 & 4 & 10 & 1.8 \\
Subgrup uygunsuzluğu & 3 & 3 & 6 & 1.1 \\
Geç anne sütü sarılığ & 3 & 2 & 5 & 0.9 \\
ABO+Subgrup uygunsuzluğu & 0 & 2 & 2 & 0.4 \\
ABO+ Rh uygunsuzluğu & 0 & 1 & 1 & 0.2 \\
Konjenital hipotiroidi & 1 & 1 & 2 & 0.4 \\
Toplam & $\mathbf{3 0 0}$ & $\mathbf{2 4 5}$ & $\mathbf{5 4 5}$ & $\mathbf{1 0 0}$ \\
\hline
\end{tabular}

* Son adet tarihine göre gestasyonel yaş 370 - 386/7 arası (28).

** Son adet tarihine göre gestasyonel yaş 390 - 416/7 arası (28).

Postnatal ilk 24 saatte IHB tanısı alan 24 olgunun 14'ünde (\%58) ABO uygunsuzluğu, 3'ünde Rh uygunsuzluğu, 2'sinde subgrup uygunsuzluğu ve 1'inde sepsis IHB nedeni olarak belirlendi. Hemolitik hiperbilirubinemi 72 (\%13.2) hastada saptandı. Hemolitik sarılığı olan yenidoğanlar etiyolojik olarak incelendiğinde en sık neden $A B O$ uygunsuzluğu olup $R h$ uygunsuzluğu ve subgrup uygunsuzluğu diğer sık nedenleri oluşturmakta idi. Hemolitik sarılığı olan grupta ortalama serum bilirubin değeri $24.3 \pm 5.4 \mathrm{mg} / \mathrm{dl}$ (12-31 mg/dl) olup hemolitik sarılığı olmayan gruptan $(20.6 \pm 4.3 \mathrm{mg} / \mathrm{dl})$ daha yüksek saptandı $(\mathrm{p}=0.021)$. IHB'li yenidoğanların 6'sına (\%1.1) kan değişimi, 5'ine (\%0.9) kan değişimi ile birlikte IVIG ve 24'üne (\%4.4) IVIG tedavisi uygulandı. Sadece IVIG tedavisi uygulanan hastalar ile kan değişimi ve IVIG tedavisi uygulanan hastalar ise hemolitik sarılığı olan yenidoğanlar idi.

Çalışmamızda, yenidoğanların 2'sinde C, 2'sinde $E$, 1 'inde c ve 1 'inde e subgrup olmak üzere toplam 6 yenidoğanda subgrup uygunsuzluğu saptanmıştır.

Kan değişimi yapılan 11 hastada en sık nedenler sırası ile ABO uygunsuzluğu $(n=6)$, Rh uygunsuzluğu $(n=2)$ ve subgrup uygunsuzluğu ( $n=1)$ idi. 2 hastada $A B O$ ve subgrup uygunsuzluğu birlikteliği saptanırken 1 hastada da $A B O$ ve Rh uygunsuzluğu birlikteliği görüldü (Tablo 3).
Tablo 3. Hemolitik Hiperbiliruninemi Nedeni ile Kan Değişimi Yapılan Hastalarda Kan Değişim Nedenleri

\begin{tabular}{lc}
\hline Nedenler & n \\
\hline ABO uygunsuzluğu & 6 \\
Rh uygunsuzluğu & 2 \\
Subgrup uygunsuzluğu & 1 \\
Sepsis & 1 \\
Bilinmeyen nedenler & 1 \\
Toplam & $\mathbf{1 1}$ \\
\hline
\end{tabular}

14 günden daha uzun süreli sarılık saptanan 10 yenidoğanın etiyolojiye yönelik yapılan değerlendirmede hastaların 5 'inde geç anne sütü sarılığı, 3'ünde idrar yolu enfeksiyonu, ve 2'sinde konjenital hipotirodi saptandı. Konjenital hipotiroidi tanısı alan hastalar tedavi başlanarak takibe alındı. Eritrosit ilişkili enzim ya da membran defekti saptanmadı.

\section{TARTIŞMA}

Sarılık, term yenidoğanda genellikle fizyolojik sarılık için tanımlanan süre olan ilk 14 gün içinde seyrini tamamlasa da etiyolojik faktörlere bağlı olarak daha uzun bir süre devam edebileceği gibi şiddeti de değişkenlik gösterebilir. Term yenidoğanların yaklaşık \%50' sinde sarılık görülmektedir (5). Bilirubine bağlı nörolojik hasar günümüzde hala önemli bir sağlık sorunudur. Yüksek bilirubin düzeyleri uygun tedavi uygulanmadığı zaman kalıcı nörolojik sekele neden olabilmektedir (1).

Literatürde, erkek cinsiyet ağır hiperbilirubinemi için risk faktörlerinden biri olarak kabul edilmektedir(5). Ülkemizde yapılan çalışmalarda erkek cinsiyet oranı $\% 55$ ile $\% 61$ arasında bildirilmiştir. Bizim çalışmamızda bu oran \%56 saptanmış olup literatür ile benzer özelliktedir (6-9).

Diyabetik annenin makrozomik bebeği de ağır hiperbilirubinemi için diğer bir risk faktörü olduğu bilinmektedir $(5,10)$. Gebelikte en sık saptanan hastalık gestasyonel diyabettir (11). ÇaIışmamız sadece term yenidoğanlardan oluşan bir popülasyon olmakla birlikte, 38 annenin diyabet tanısı ile izlendiği veya gestasyonel diyabet tanısı aldığı ve 13 yenidoğanın diyabetik annenin makrozomik bebeği olduğu saptanmıştır.

Anne sütü ile beslenememe, çalışmamızda İHB'nin sık sebepleri arasında yer almakla birlikte Ünal ve ark.'nın bildirdiğinin aksine en sık neden olarak saptanmamıştır (8). Çalışma popülasyonunun term yenidoğanlardan oluşması ve popülasyondaki düşük doğum ağırlıklı bebek oranının belirtilen çalışmaya göre daha düşük olmasının buna neden olabileceği düşünülmektedir. Anne sütü ile beslenememe, hipernatremik dehidratasyon 
açısından da risk taşımaktadır. Hipernatremi insidansı anne sütü ile beslenenlerde, özellikle yaşı 14 günden küçük yenidoğanlarda daha yüksektir (12). Günümüzde hipernatremik dehidratasyonun en sık sebebinin yetersiz hacimde anne sütü ile beslenme olduğu bilinmektedir. Bunun yanı sıra primer laktasyon yetersizliği nadir görülürken, anne sütünün memeden boşaltılamaması ve meme angorjmanı sekonder laktasyon yetersizliği gibi emzirmedeki teknik yanlışlıklar sonucu ortaya çıkmaktadır (13). Kanada'da yapılan bir çalışma doğum sonrası hastane yatış süresinin kısalmasının hastaneye geri yatış oranlarını belirgin olarak artırı̆ı̆ı, dehidratasyon, sarılık, beslenme problemi ve yetersiz kilo alımına da neden olduğunu bildirmektedir (14). Erken emzirmeye başlama, doğru emzirme tekniklerinin öğretilmesi, devamlıı̆ı̆ın sağlanması ve başta anne olmak üzere ailenin anne sütü ile besleme konusunda desteklenmesi büyük öneme sahiptir.

IHB'nin diğer bir sık nedeni olarak saptanan DDA, aynı zamanda Dünya Sağlık Örgütü tarafından genel sağlık göstergelerinden biri olarak kabul edilmektedir. DDA prevelansı ülkeler arasında $\% 5$ ile \%19 arasında değişmekte olup neonatal mortalitenin en önemli nedenlerinden biridir $(15,16)$. Ayrıca DDA olan yenidoğanlarda, doğum asfiksisi, solunum sıkıntısı, sepsis, İHB, hipoglisemi, polisitemi ve konjenital malformasyon riski, normal doğum ağırlığına sahip yenidoğanlara kıyasla çok daha yüksektir (17). Bu nedenle DDA'lı yenidoğanlar sözü edilen morbiditeler açısından da yakın izlem gerektirir. Çalışmamızda DDA prevelansı $\% 16$ olarak bulunmuştur.

Term bebeklerde iki haftadan, preterm bebeklerde üç haftadan uzun süren sarılıklar uzamış sarılık olarak tanımlanır. Uzamış sarılıkların büyük çoğunluğu anne sütü sarılığı olmakla birlikte diğer patolojik nedenlerin dışlanması gerekir (18). Geç başlangıçlı anne sütü sarıı̆̆ı genellikle yaşamın ilk haftasından sonra ortaya çıkar ve üçüncü aya kadar devam edebilir. Ünal ve ark.'nın çalışmalarında geç anne sütü sarıı̆ıın \%2.3 oranında bildirmişlerdir(8). Çalışmamızda bu oran \%0.9 olarak bulunmuştur.

Kan grubu uyuşmazlıkları IHB nedenlerinin başında gelmektedir. Geçmişte en sık neden Rh uygunsuzluğu iken, Rh immünglobulin kullanımı ile Rh izoimmünizasyonu sıklığı azalırken diğer kan grupları ile ilişkili uygunsuzluk artış göstermiştir (19). Çalışmamızda en sık IHB nedeni ABO uygunsuzluğu (\%28.6) olup bunu sırası ile Rh uygunsuzluğu (\%2.2) ve subgrup uygunsuzluğu (\%1.1) takip etmektedir. 1 hastada $A B O+R h$ uygunsuzluğu ve 2 hastada $A B O+$ subgrup uygunsuzluğu birlikteliği saptanmıştır. 2000-2005 yılları arasında ülkemizde yapılan ça-
Iışmalarda IHB etiyolojisinde \%8-15 oranında Rh uygunsuzluğu daha sık saptanırken bu oran 2008 de Ünal ve ark.'nın yaptığı çalışmada \%2 oranında bildirilmiş olup $A B O$ uygunsuzluğunun sıkığının arttığı görülmektedir (6-8). Özdemir ve ark. İHB nedeni ile kan değişimi yapılan hastalarda $A B O$ uygunsuzluğunu, $R h$ uygunsuzluğundan daha sık olarak bildirmişlerdir (20). Karagöl ve ark. subgrup uyuşmazlığına sekonder hemolitik hastalığı olan 106 yenidoğan ile yaptığı çalışmada C, E ve C subgrup uygunsuzluğunun oranlarını sırası ile $\% 37, \% 30$ ve $\% 22$ olarak bildirmişlerdir (3). Buna karşın başka bir çalışmada Kell, E, ve c subgrup uygunsuzluğu daha sık olarak bildirilmektedir (20). Çalışmamızda, yenidoğanların 2'sinde C, 2'sinde E, 1'inde c ve 1 'inde e subgup olmak üzere toplam 6 yenidoğanda subgrup uygunsuzluğu saptanmıştır. Anne kan grubu $O$ veya $\mathrm{Rh}(-)$ olan bebeklerde kan grubu hızla çalışımalı ve IHB açısından izlenmelidir. Nedeni bilinmeyen hemolitik sarılıklarda subgrup uygunsuzlukları açısından da değerlendirme yapıımalıdır.

Yenidoğan döneminde semptomatik idrar yolu enfeksiyonu insidansı yaklaşık \%1 olup sarılık, kusma, beslenme yetersizliği, yetersiz kilo alımı, aktivitede azalma gibi semptomlar görülebilir. İHB etiyolojisi ayırıcı tanısında yer alan ve tedavi edilmediği takdirde ölüme yol açabilecek bir enfeksiyondur (21). Çalışmamızda 10 hastada (\%1.8) idrar yolu enfeksiyonu saptanmış olup Ünal ve ark.'nın yaptığı çalışmadaki idrar yolu enfeksiyonu oranı (\%1) ile benzerlik göstermektedir (8).

Sepsis, yenidoğan döneminde sık görülen enfeksiyon dışı nedenlerde de görülen özgül olmayan bulgularla da klinik olarak karşımıza çıkabilir. Bu nedenle tanı koymada zorluklar yaşanabilen ancak hayati öneme sahip bir durumdur. Erken ve geç sepsis, İHB etyolojisinde mutlaka akılda tutulmalıdır (21). Çalışmamızda sepsis oranı $\% 2$ olarak bulunmuştur. Tekinalp ve ark. sepsis oranını \% 3.6, Kılıç ve ark. \%1.8 olarak bildirmişlerdir $(22,23)$. Sepsis, hem IHB hem de uzamış sarılık etiyolojisinde ayırıcı tanıda mutlaka akla gelmelidir.

IHHB yenidoğan döneminde sık görülen, genellikle spontan düzelme eğiliminde olan iyi seyirli bir süreçtir. Ancak zamanında tanı konup tedavi edilmeyen yüksek bilirubin düzeylerinin yol açacağı bilirubin ensefalopatisi ciddi nörolojik sekellere neden olur (20). Tedavi seçenekleri fototerapi, kan değişimi ve farmakolojik tedavidir. IVIG, farmakolojik tedavi seçeneklerinden biri olup sıklıkla intrauterin transfüzyon yapılmış, direkt Coombs testi pozitif saptanan $\mathrm{Rh}, \mathrm{ABO}$ ve subgrup uygunsuzluğu olan bebeklerde kullanılmaktadır (24). Çalışmamızda tüm hastalara fototerapi uygulanmıştır. Hemolitik hastalık veya ciddi hiperbilirubinemisi olan 6 hastaya kan değişimi, 24 hastaya IVIG 
tedavisi uygulanmıştır. 5 hastaya ise kan değişimi ile birlikte IVIG tedavisi uygulanmıştır. Çalışmamızda, literatür ile benzer şekilde $A B O$ uygunsuzluğuna bağlı ağır hiperbilirubineminin en sık kan değişimi endikasyonu olduğu görülmektedir (25). Kan değişimi yapılan hastalarda kan değişimi ile ilişkili herhangi bir komplikasyon izlenmemiştir.

Çalışmamızda nedeni açıklanamayan hemoliz bulguları ve retikülositozu olan veya hematokrit değerinde düşme olan hastalardan glukoz-6-fosfat dehidrogenaz ve pirüvatkinaz enzim düzeyi için örnek gönderilmiş ancak bu hastalarda herhangi bir enzim defekti saptanmamıştır. Ancak G6PD eksikliği yenidoğan döneminde sadece hemoliz ile değil, hemoliz olmadan da karaciğerde bilirubin metabolizmasının etkilenmesine bağlı İHB oluşmakta ve çoğunlukla neden bu olmaktadır (26). Ülkemizden yapılan bir çalışmada G6PD enzim düzeyi düşük ve normal çıkan İHB'li yenidoğanlarda hemotalojik parametreler açısından bir fark bulunmadığı görülmektedir (27). Bu nedenle tedavi gerektiren sarılığı olan tüm yenidoğanlarda G6PD eksikliği taranmalıdır. Bu çalışmanın kısıtıılarından birini oluşturmaktadır. Merkezimiz geniş bir bölgeye hizmet veriyor olmasına karşın çalışmanın tek merkezli bir çalışma olması, çalışmanın bir diğer kısıtlıığını oluşturmaktadır. Buna ek olarak sadece term yenidoğanların çalışmaya dahil edilmesi ve prematüre yenidoğanları içermemesi nedeni ile tüm yenidoğanlar için etyoloji açısından sonuç verememektedir.

\section{SONUÇ}

IHB yenidoğan döneminin sık görülen sorunlarından biri olup ağır hiperbilirubinemisi olan hastalarda da zamanında tanı ve tedavi ile iyi prognoza sahiptir. Erken tanı, altta yatan nedeni zamanında belirlenmesi ve doğru hasta yönetimi bu sonuca etki edecek en önemli faktörlerdir. Kan grubu uygunsuzluğu, düşük doğum ağırlığı, anne sütü ile beslenmedeki eksiklikler gibi altta yatan risk faktörlerinin dikkate alınarak izlem yapılması büyük öneme sahiptir.

Etik Kurul Onayı: Bu çalışma için Uludağ Üniversitesi Tıp Fakültesi Klinik Araştırmalar Etik Kurulu'nun 09.12.2020 tarih ve 2020-22/3 karar numaralı onayı alınmıştır.

Çıkar Çatışması: Yazarlar çıkar ilişkisi olmadığını beyan eder.

\section{KAYNAKLAR}

1.Lee BK, Le Ray I, Sun JY, Wikman A, Reilly M, Johansson S. Haemolytic and non haemolytic neonatal jaundice have different risk factor profiles. Acta Paediatrica, 2016;105(12):144450.

2.Wong RJ. Neonatal jaundice and liver diseases. In: Martin RJ, Fanaroff AA, Walsh MC (eds). Neonatal-Perinatal Medicine. Diseases of the Fetus and Infant..8th ed.Philadelphia: Mosby Elsevier. 2006:1419-65

3. Karagol BS, Zenciroglu A, Okumus N, Karadag N, Dursun A, Hakan N. Hemolytic disease of the new born caused by irregular blood subgroup (Kell, C, C, E, and e) incompatibilities: report of 106 cases at a tertiary-carecentre. Am J Perinatol. 2012;29(6):449-54.

4. Subcommittee on Hyperbilirubinemia, Clinical Practice Guideline, American Academy of Pediatrics: Management of the newborn 35 or more weeks of gestation. Pediatrics. 2004;114:297-316.

5. Maisels MJ, Bhutani VK, Bogen D, Newman TB, Stark $A R$, Watchko JF. Hyperbilirubinemia in the newborn infant $\geq 35$ weeks gestation: an update with clarification. Pediatrics. 2009;124:1193-8.

6. Narlı N, Satar M, Özlü F, Yapıcıoğlu HY, Özcan K. Çukurova Üniversitesi Yenidoğan Yoğun Bakım Ünitesi'ne yatırılan hiperbilirubinemili bebeklerin etiyolojik yönden değerlendirilmesi. Çukurova Üniversitesi Tıp Fakültesi Dergisi. 2004;29:51-5.

7.Özkaya H, Bahar A, Özkan A, Kandemir F, Göçmen İ, Mete Z. İndirekt hiperbilirubinemili yenidoğanlarda $A B O$, Rh ve subgrup (Kell, c,e) uyuşmazlıkları. Türk Pediatri Arşivi. 2000;35:30-5.

8. Ünal S, Eker S. İndirekt Hiperbilirubinemili Yenidoğanların Geriye Dönük Olarak Değerlendirilmesi. Türkiye Klinikleri J Pediatr. 2008;17(4):223-9.

9.IIlhan Ö, Özer EA, Sütçüoğlu S, Alkan S. Yenidoğan Sarıı̆ğ Nedeni ile Hastaneye Yatırılan Olgularda Tedavi Kılavuzlarına Uyumun Araştıııması. Selçuk Tıp Derg. 2014;30(1):8-11.

10.Schwartz HP, Haberman BE, Ruddy RM. Hyperbilirubinemia Current Guidelines and Emerging Therapies. Pediatric Emergency Care.2011:27(9):884-889.

11. Deputy NP, Kim SY, Conrey EJ, Bullard KM. Prevalence and Changes in Preexisting Diabetes and Gestational Diabetes Among Women Who Had a Live Birth — United States, 20122016. Centers for Disease Control and Prevention. Morbidity 
and Mortality Weekly Report. 2018;Vol. 67:No. 43.

12. Forman S, Crofton $P$, Huang $H$, Marshall T, Fares K, Mclntosh $\mathrm{N}$. The epidemiology of hypernatraemia in hospitalised children in Lothian: a 10-year study showing differences between dehydration, osmoregulatory dysfunction and salt poisoning. Arch Dis Child. 2012;97:502-7.

13. Kültürsay N, Çalkavur Ş. İndirekt hiperbilirubinemi: nedenler ve tanı. Güncel Pediatri. 2006;2:21-5.

14. Liu S, Wen SW, McMillan D, Trouton K, Fowler D, McCourt

C. Increased neonatal readmission rate associated with decreased length of hospitalstay at birth in Canada. Can J Public Health. 2000;91:46-50.

15. Wardlaw TM. Low Birth Weight: Country, Regional and Global Estimates, UNICEF and WHO Publications 2004.

16. Liu L, Oza S, Hogan D, Chu Y, Perin J, Zhu J, et al. Global, regional, and national causes of under-5 mortality in 2000-15: an updated systematic analysis with implications for the Sustainable Development Goals. Lancet.2016;388(10063):3027-35.

17. Klaus L, Fanaroff M. Care of The High Risk Neonate, 3rd ed. Philadelphia: WB Saunders, 1986.

18. Çoban A, Kaynak Türkmen M, Gürsoy T. Turkish Neonatal Society guideline to the approach, follow-up, and treatment of neonatal jaundice. Turk Pediatri Ars. 2018 ;53(Suppl 1):S172-S179.

19. Sharma D, Farahbakhsh N. Neonatal hyperbilirubinemia secondary to combined Anti e and Anti $C$ isoimmunisation: a literature review, The Journal of Maternal-Fetal \& Neonatal Medicine.2019;32(12):2009-11.

20. Özdemir SA, Özer EA, İlhan Ö, Sütçüoğlu S. İndirekt hiperbilirubinemi nedeni ile kan değişimi yapılan yenidoğan bebeklerin değerlendirilmesi: Tek merkez deneyimi. İzmir Dr. Behçet Uz Çocuk Hast. Dergisi 2017;7(3):236-41.
21. Satar M, Arısoy AE. Türk Neonatoloji Derneği Yenidoğan Enfeksiyonları Tedavi ve İzlem Kılavuzu.2014;1-28.

22. Kıııç İ, Ergin H, Çakaloz I. The Evaluation of Indirect Hyperbilirubinemia cases in Newborn Period. Türkiye Klinikleri J Pediatr. 2005;14:20-5.

23. Tekinalp G, Ergin H, Erdem G, Yurdakök M, Yiğit Ş. Yenidoğan döneminde uzamış sarılıklar: 82 vakanın değerlendirilmesi. Çocuk Sağıı̆ı ve Hastalıkları Dergisi. 1996; 39:441-8.

24. Çoban A, Türkmen M, Gürsoy T. Türk Neonatoloji Derneği Yenidoğan Sarılıklarında Yaklaşım, İzlem ve Tedavi Rehberi. 2014;1-36.

25. Lopriore E, Rath ME, Liley H, Smits-Wintjens VEHJ. Improving the management and outcome in haemolytic disease of the foetus and newborn. Blood Transfusion. 2013:(4):484-96.

26. Jalloh S, Van Rostenberghe H, Yusoff NM, Ghazali S, Nik Ismail NZ, Matsuo M, et al. Poor correlation between hemolysis and jaundice in glucose-6-phosphate dehydrogenase deficient babies. Pediatr Int. 2005;47(3):258-61. http://dx.doi.org/10.1111/j.1442-200x.2005.02052.x PMID:15910447.

27. İlker Günay. Yenidoğan sarılığına G6PD eksikliğinin etkisi. İzmir Dr. Behçet Uz Çocuk Hast. Dergisi 2011; 1(3):115-120. doi:10.5222/buchd.2011.115.

28. Fleischman AR, Oinuma M, Clark SL. Rethinking the Definition of "Term Pregnancy". Obstet Gynecol. 2010; 116:136-139. doi: 10.1097/AOG.0b013e3181e24f28. PMID:20567179. 